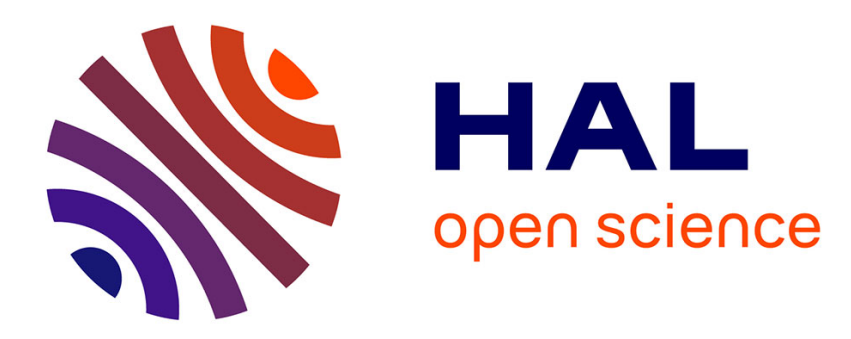

\title{
Histologic diagnosis in young women with breast cancer
}

Francisco Javier Andreu

\section{To cite this version:}

Francisco Javier Andreu. Histologic diagnosis in young women with breast cancer. Breast Cancer Research and Treatment, 2010, 123 (s1), pp.15-18. 10.1007/s10549-010-1060-3 . hal-00565559

\section{HAL Id: hal-00565559 \\ https://hal.science/hal-00565559}

Submitted on 14 Feb 2011

HAL is a multi-disciplinary open access archive for the deposit and dissemination of scientific research documents, whether they are published or not. The documents may come from teaching and research institutions in France or abroad, or from public or private research centers.
L'archive ouverte pluridisciplinaire HAL, est destinée au dépôt et à la diffusion de documents scientifiques de niveau recherche, publiés ou non, émanant des établissements d'enseignement et de recherche français ou étrangers, des laboratoires publics ou privés. 
Manuscript Type: Brief article

\section{Histologic diagnosis in young women with breast cancer}

Francisco Javier Andreu ${ }^{1}$

${ }^{1}$ Corporació Sanitària Parc Taulí, Sabadell (Barcelona), Spain.

Corresponding author:

Francisco Javier Andreu, MD

Department of Pathology

UDIAT Centre Diagnòstic

Corporació Sanitària Parc Taulí,

Parc Taulí, S/N

08208-Sabadell (Barcelona). Spain

E-mail: $\quad$ fjandreu@mac.com

Phone: $\quad+34937231010$

Fax: $\quad+34937160646$ 


\section{Introduction}

Breast cancer is a heterogeneous group of tumors with similar diagnostic, but different prognostic profiles that can be subdivided on the basis of histopathological features, genetic alterations and gene-expression profiles. The World Health Organization has defined a wide range of histopathological subtypes of invasive breast cancer and classified these carcinomas into 19 categories, most of which are quite rare [1]. This classification into tumor subtypes is based on histopathological characteristics, and reflects differences in biological behavior and, in general lines, different outcomes. However, the main criticism to this classification is that $>80 \%$ of the tumor subtypes are infiltrating ductal carcinomas not otherwise specified (NOS). For this reason, histological grading systems, which do have prognostic value, have been elaborated.

Using an intrinsic set of 534 genes, Sørlie et al. [2] analyzed the expression profiles of 115 independent breast tumor samples and categorized breast tumors into five groups:

1) Iuminal $A$; 2) luminal $B$; 3) human epidermal growth factor receptor-2 (HER2) enriched (i.e. tumors that overexpress ErbB2-associated genes but do not express genes that define the luminal subtype); 4) normal breast-like; and 5) basal-like. Each group of tumors has different prognoses and clinical outcomes.

\section{Histological subtypes of breast cancer}

\section{Luminal $A$ and luminal B tumors}

The traditional division of breast cancers into "endocrine receptor positive or negative" helps guide patient management. Luminal subtype $A$ and $B$ tumors express estrogen receptors (ER), GATA3, and genes regulated by both ER and GATA3 [3, 4]. Compared with luminal B tumors, luminal A tumors express higher levels of ER and GATA3 and show more favorable patient outcomes in both the presence and the absence of systemic adjuvant therapy [2], whereas luminal B tumors more often express human epidermal growth factor receptor-1 (HER1 or epidermal growth factor receptor [EGFR]), 
HER2, and/or cyclin E1 [2, 5]. Although some luminal B tumors can be identified by their expression of HER2 (HER2 positive or HER2+), the major biological distinction between luminal $A$ and $B$ is the proliferation signature, including genes such as CCNB1, MYBL2, and MKI67 (encoding Ki-67), which have a higher expression in luminal B tumors than in luminal A tumors [6].

Breast cancers expressing high levels of $\mathrm{Ki}-67$, a nuclear marker of cell proliferation, are associated with worse outcomes [7]. As suggested from gene-expression profiling, coexpression of HER2 and ER and/or progesterone receptor (PR) can identify some luminal B tumors (i.e., the luminal - HER2+ group). However, only approximately $30 \%$ of luminal B tumors are HER2+, indicating that this clinical marker alone is not sensitive enough to identify most luminal B breast cancers [8]. Ki-67 can be added concurrently to the standard biomarker panel of ER, PR, and HER2 to identify additional luminal $\mathrm{B}$ tumors that would not be identified by these three markers [8].

\section{HER2 enriched tumors}

HER2+ tumors fall into at least two distinct expression groups: those which are ERand typically cluster near basal-like tumors (HER2+/ER- subtype), and those which are $\mathrm{ER}+$ (which may also be $\mathrm{PR}+$ ) and cluster with tumors of luminal cell origins as part of the luminal B subtype $[2,5]$.

\section{Basal-like tumors}

Basal-like tumors typically show low expression of HER2 and ER and exhibit high expression of genes that characterize the basal epithelial cell layer, including genes responsible for the expression of cytokeratins 5,6 , and 17 [10]. There is some confusion in the literature as to what defines a basal-like tumor. The term was introduced by Perou et al. [10] as describing a subgroup of tumors defined by their great similarity in overall gene-expression pattern of the "intrinsic gene subset" when 
unsupervised hierarchical clustering was applied. As outlined above, several studies have indicated that these basal-like tumors have low mRNA expression of $E R, P R$ and HER2 genes, and are usually also negative for expression of ER, PR and HER2 measured using immunohistochemistry.

\section{Epidemiological data of breast cancer subtypes}

The prevalence among these subtypes of breast cancer in young women varies from one study to another [11, 12]. In a study by Lin et al. [11], younger ( $<50$ years) breast cancer patients had a higher prevalence of luminal A (67\%) and a lower prevalence of basal-like (9\%) subtype. The higher prevalence of luminal A subtype in this study population was mainly attributed to a higher ER and PR expression rate in younger patients than in older patients.

Also in the study by Ihemelandu et al. [12], the luminal A subtype was the most prevalent (50\%) compared with basal-like (23\%), luminal B (14\%), and HER2 (13\%) subtypes. However, when stratified by age groups, results showed that in women under 35 years the basal-like subtype was the most prevalent (56\%), in comparison with $26 \%, 15 \%$, and $6 \%$ for luminal A, luminal $\mathrm{B}$, and HER2 subtypes, respectively.

Other important results from this study regarding women younger than 35 years of age were that $P 53$ mutations were more prevalent in basal-like subtypes compared with luminal A subtypes (48\% vs 19\%). Luminal B subtypes are more likely to overexpress the $\mathrm{Bcl}-2$ gene than luminal A subtypes. Though not statistically significant, HER-2/neu and basal-cell-like subtypes had the shortest survival time [12]. The high prevalence of the basal-like subtype in young premenopausal women aged $<35$ years may contribute to the poorer prognosis observed in this cohort of women.

The probability of remaining disease-free is significantly different between subtypes; patients with luminal A type tumors live considerably longer before they develop metastatic disease, whereas the basal-like and HER2 subtypes show much shorter 
disease-free time intervals [2]. The basal-like subtype has been associated with poor clinical outcomes $[2,13]$, which likely reflect this subtype's high proliferative capacity [2, $5,13]$ as well as the lack of directed therapies, since typically basal-like tumors do not express ER or overexpress HER2 [14].

\section{Histological characterization of basal-like breast cancers}

Among the five intrinsic subtypes, basal-like breast cancers have drawn particular attention, because they do not express ER, PR, or HER2 (i.e. triple negative tumors), and therefore are not be expected to benefit from anti-estrogen therapies nor from trastuzumab [15].

Approximately $80 \%$ to $90 \%$ of triple negative breast cancers are deemed to be basallike when appropriately tested for immunohistochemical markers and gene expression. Moreover, there is a consistent trend across studies confirming unfavorable clinical outcomes associated with the triple negative phenotype and basal-like breast cancer $[5,14,16]$

Additional efforts have been made to characterize basal-like tumors with standard histopathology and immunohistochemical analyses [14, 17]. Nielsen et al. identified a panel of antibodies (anti ER, EGFR, HER2 and cytokeratin 5/6) that could accurately discriminate basal-like tumors from the other molecular subtypes. They used a panel of 21 basal-like tumors defined by gene-expression profiling, and correlated their immunohistochemical features with those obtained from a series of 663 breast tumors. They found that $15 \%$ were of the basal-like subtype and all of them stained negative for ER, PR and HER2 and positive for cytokeratin 5/6 and/or EGFR [14].

In another study, Kim et al. studied 776 breast tumors using immunohistochemistry, which were subdivided into five groups based on the pattern of marker expression. Basal-like tumors were defined by negative staining for ER, PR and HER2, and positive 
staining for cytokeratin 5 and/or cytokeratin 14 and/or EGFR and/or cKIT [17]. This subtypes were also associated with TP53 mutations [5].

Recently, in a microarray study of basal cytokeratin expression and related immunohistochemical markers, breast cancers that were positive for cytokeratin $5 / 6$ were found to be associated with expression of EGFR, with the proliferation marker Ki67, with accumulation of p53 and with increased cytogenetic abnormalities [18]. In another recent study, the basal-like subtype, as defined by cytokeratin $5 / 6$ expression by immunohistochemistry, was also found to be common among breast cancer patients with hereditary BRCA1 mutations [19].

BRCA1-associated breast carcinomas usually have a basal-like phenotype [10], are of higher grade (usually grade 3), have a higher mitotic count, are TP53-mutated, are ER and HER2 negative, and are characterized by the expression of basal or myoepithelial markers such as basal keratins, P-cadherin and EGFR [19-22]. On the other hand, BRCA2-associated breast carcinomas are rarely basal-like phenotype, also are of higher grade (usually grade 2/3) than sporadic age-matched controls [21], and tend to be ER and PR positive [23].

The observation that $B R C A 1$ mutations are strongly associated with a basal tumor phenotype indicates a particularly poor prognosis for patients carrying this mutation. $B R C A 1$ status in familial cancers has failed to be an independent prognostic factor in several studies [24], and is complicated by confounding factors such as frequent screening and early diagnosis.

\section{Conclusions}

Breast cancer can be categorized into five histological groups such as luminal A, luminal B, HER2+, normal breast-like, and basal-like. Prevalence of breast cancer in young women varies from one study to another, but based in its histological characteristics is thought that young women have a higher prevalence of basal-like 
subtype. Patients with luminal A type tumors live considerably longer before they develop metastatic disease. The basal-like subtype has been associated with poor clinical outcomes, and with a shorter relapse-free and overall survival than luminal tumors.

Basal-like breast cancers do not express ER, PR, or HER2, and therefore are not expected to benefit from antiestrogen therapies nor from trastuzumab. Basal-like tumors are defined by negative staining for ER, PR and HER2, and positive staining for cytokeratin 5, 6 and/or cytokeratin 14 and/or EGFR and/or cKIT, accumulation of p53 and with the proliferation marker Ki-67. BRCA1-associated breast carcinomas are usually of the basal-like subtype. The observation that $B R C A 1$ mutations are strongly associated with a basal-like tumor phenotype indicates particularly poor prognosis in patients carrying this mutation. 


\section{Acknowledgements}

The authors acknowledge the support of Pfizer Spain, which facilitated the necessary meetings to evaluate and discuss all the data presented in this review, and Dr. Fernando Sánchez-Barbero from HealthCo SL (Madrid, Spain) for assistance in the preparation of this manuscript. 


\section{References}

1. Tavassoli FA, Devilee P (2003) World Health Organization of Tumours. Pathology and genetics of tumours of the breast and female genital organs. IARCpress. Lyon

2. Sorlie T, Tibshirani R, Parker J, Hastie T, Marron JS, Nobel A, et al. (2003) Repeated observation of breast tumor subtypes in independent gene expression data sets. Proc Natl Acad Sci U S A 100:(14):8418-23

3. Usary J, Llaca V, Karaca G, Presswala S, Karaca M, He X, et al. (2004) Mutation of GATA3 in human breast tumors. Oncogene 23:(46):7669-78

4. Finlin BS, Gau CL, Murphy GA, Shao H, Kimel T, Seitz RS, et al. (2001) RERG is a novel ras-related, estrogen-regulated and growth-inhibitory gene in breast cancer. J Biol Chem 276:(45):42259-67

5. Sorlie T, Perou CM, Tibshirani R, Aas T, Geisler S, Johnsen H, et al. (2001) Gene expression patterns of breast carcinomas distinguish tumor subclasses with clinical implications. Proc Natl Acad Sci U S A 98:(19):10869-74

6. Perou CM, Jeffrey SS, van de Rijn M, Rees CA, Eisen MB, Ross DT, et al. (1999) Distinctive gene expression patterns in human mammary epithelial cells and breast cancers. Proc Natl Acad Sci U S A 96:(16):9212-7

7. de Azambuja E, Cardoso F, de Castro G, Jr., Colozza M, Mano MS, Durbecq V, et al. (2007) Ki-67 as prognostic marker in early breast cancer: a meta-analysis of published studies involving 12,155 patients. Br J Cancer 96:(10):1504-13

8. Cheang MC, Chia SK, Voduc D, Gao D, Leung S, Snider J, et al. (2009) Ki67 index, HER2 status, and prognosis of patients with luminal B breast cancer. J Natl Cancer Inst 101:(10):736-50

9. Cheang MC, Voduc D, Bajdik C, Leung S, McKinney S, Chia SK, et al. (2008) Basal-like breast cancer defined by five biomarkers has superior prognostic value than triple-negative phenotype. Clin Cancer Res 14:(5):1368-76 
10. Perou CM, Sorlie T, Eisen MB, van de Rijn M, Jeffrey SS, Rees CA, et al. (2000) Molecular portraits of human breast tumours. Nature 406:(6797):747-52

11. Lin CH, Liau JY, Lu YS, Huang CS, Lee WC, Kuo KT, et al. (2009) Molecular subtypes of breast cancer emerging in young women in Taiwan: evidence for more than just westernization as a reason for the disease in Asia. Cancer Epidemiol Biomarkers Prev 18:(6):1807-14

12. Ihemelandu CU, Leffall LD, Jr., Dewitty RL, Naab TJ, Mezghebe HM, Makambi $\mathrm{KH}$, et al. (2007) Molecular breast cancer subtypes in premenopausal AfricanAmerican women, tumor biologic factors and clinical outcome. Ann Surg Oncol 14:(10):2994-3003

13. Sotiriou C, Neo SY, McShane LM, Korn EL, Long PM, Jazaeri A, et al. (2003) Breast cancer classification and prognosis based on gene expression profiles from a population-based study. Proc Natl Acad Sci U S A 100:(18):10393-8

14. Nielsen TO, Hsu FD, Jensen K, Cheang M, Karaca G, Hu Z, et al. (2004) Immunohistochemical and clinical characterization of the basal-like subtype of invasive breast carcinoma. Clin Cancer Res 10:(16):5367-74

15. Slamon DJ, Leyland-Jones B, Shak S, Fuchs H, Paton V, Bajamonde A, et al. (2001) Use of chemotherapy plus a monoclonal antibody against HER2 for metastatic breast cancer that overexpresses HER2. $\mathrm{N}$ Engl $\mathrm{J}$ Med $344:(11): 783-92$

16. Bauer KR, Brown M, Cress RD, Parise CA, Caggiano V (2007) Descriptive analysis of estrogen receptor (ER)-negative, progesterone receptor (PR)negative, and HER2-negative invasive breast cancer, the so-called triplenegative phenotype: a population-based study from the California cancer Registry. Cancer 109:(9):1721-8

17. Kim MJ, Ro JY, Ahn SH, Kim HH, Kim SB, Gong G (2006) Clinicopathologic significance of the basal-like subtype of breast cancer: a comparison with 
hormone receptor and Her2/neu-overexpressing phenotypes. Hum Pathol $37:(9): 1217-26$

18. Korsching E, Packeisen J, Agelopoulos K, Eisenacher M, Voss R, Isola J, et al. (2002) Cytogenetic alterations and cytokeratin expression patterns in breast cancer: integrating a new model of breast differentiation into cytogenetic pathways of breast carcinogenesis. Lab Invest 82:(11):1525-33

19. Foulkes WD, Stefansson IM, Chappuis PO, Begin LR, Goffin JR, Wong N, et al. (2003) Germline BRCA1 mutations and a basal epithelial phenotype in breast cancer. J Natl Cancer Inst 95:(19):1482-5

20. Honrado E, Benitez J, Palacios J (2005) The molecular pathology of hereditary breast cancer: genetic testing and therapeutic implications. Mod Pathol 18:(10):1305-20

21. (1997) Pathology of familial breast cancer: differences between breast cancers in carriers of BRCA1 or BRCA2 mutations and sporadic cases. Breast Cancer Linkage Consortium. Lancet 349:(9064):1505-10

22. Grushko TA, Blackwood MA, Schumm PL, Hagos FG, Adeyanju MO, Feldman MD, et al. (2002) Molecular-cytogenetic analysis of HER-2/neu gene in BRCA1associated breast cancers. Cancer Res 62:(5):1481-8

23. Robson ME, Chappuis PO, Satagopan J, Wong N, Boyd J, Goffin JR, et al. (2004) A combined analysis of outcome following breast cancer: differences in survival based on BRCA1/BRCA2 mutation status and administration of adjuvant treatment. Breast Cancer Res 6:(1):R8-R17

24. Kennedy RD, Quinn JE, Johnston PG, Harkin DP (2002) BRCA1: mechanisms of inactivation and implications for management of patients. Lancet $360:(9338): 1007-14$ 